\title{
A IMPORTÂNCIA DA CRIAÇÃO DO BANCO NACIONAL DE PERFIS GENÉTICOS PARA A PERÍCIA CRIMINAL
}

\author{
Yasmin Teixeira Cavalcante de Lima* \\ Centro Universitário Tiradentes, Maceío, AL, Brasil \\ Marek Henryque Ferreira Ekert \\ Laboratório Forense da Perícia Oficial de Alagoas, Maceió, AL, Brasil
}

\section{THE IMPORTANCE IN CREATING THE NATIONAL DNA DATABASE FOR THE CRIMINAL EXPERTISE}

\begin{abstract}
RESUMO
A lei n¹2.654/12 prevê a coleta de material genético como forma de identificação criminal. Em 2013, o Banco Nacional de Perfis Genéticos foi criado com o propósito de armazenar dados de perfis genéticos coletados para subsidiar ações destinadas à apuração de crimes, tais como aqueles coletados de condenados por crimes violentos contra a pessoa, hediondos e equiparados. A coleta é realizada com o uso de um swab. A obtenção do perfil genético é de responsabilidade de um Perito Criminal, designado para tal função. $O$ presente trabalho objetivou demonstrar a importância da criação do Banco Nacional de Perfis Genéticos para as Ciências Forenses, apresentando os benefícios desse banco de dados para a sociedade. Buscou-se, com esse trabalho, esclarecer dúvidas sobre a necessidade e importância de um banco de perfis genéticos para a sociedade e para a investigação, assim como colaborar com o conhecimento a respeito do referido banco de dados. O presente estudo evidenciou a grande importância que o Banco Nacional de Perfis Genéticos possui na esfera forense e o quanto ele vem auxiliando não só na elucidação de crimes, como também, no combate de injustiças como, por exemplo, inocentando indivíduos indevidamente condenados.
\end{abstract}

PALAVRAS-CHAVE: Banco nacional de perfis genéticos. DNA. Ciências forenses. Lei no 12.654/12.

\begin{abstract}
Law $n^{\circ} 12.654 / 12$ allows the collection of genetic material as a form of criminal identification. In 2013, the National DNA Database was created with the purpose of storing genetic profiles to support crime investigations, such as those collected from offenders convicted of crimes against the person, heinous crimes and similar. The collection is carried out through the use of a swab. The obtention of genetic profiles is responsibility of a forensic expert, designated for this function. This work aimed to demonstrate the importance of creating the National DNA Database for forensics sciences, presenting the benefits of this database to society. It is expected to clarify questions about the need for and importance of a DNA Database for society and for the criminal investigation, as well as to collaborate with the knowledge about this tool. This study showed the great importance that the National DNA Database has in the forensic sphere and how much it has been supporting not only in the elucidation of crimes, but also in the fight against injustices, such as, for example, acquitting wrongfully convicted individuals.
\end{abstract}

KEYWORDS: National DNA database. DNA. Forensic sciences. Law $n^{\circ}$ 12.654/12. 


\section{INTRODUÇÃo}

Em 2012 foi sancionada a Lei $n^{\circ} 12.654$, que alterou as Leis $n^{\circ} 12.037 / 09$ (Lei de Identificação Criminal) e $n^{\circ} 7.210 / 84$ (Lei de Execução Penal), que prevê a coleta de perfil genético como forma de identificação criminal ${ }^{1}$. O Banco Nacional de Perfis Genéticos (BNPG) foi criado em 2013, a partir do Decreto $n^{0}$ 7.950, visando armazenar dados de perfis genéticos coletados para subsidiar ações destinadas à apuração de crimes, tais como aqueles coletados de condenados por crimes violentos contra a pessoa, hediondos e equiparados. Os dados de perfis genéticos correspondentes a cada coleta são armazenados neste banco de dados, registrando as informações genéticas dos condenados. A responsabilidade de gerenciamento deste banco de dados é de um Perito Criminal Oficial, designado para tal função.

A coleta desse material genético deve ser realizada de forma indolor, podendo ser obtido por meio da saliva, no que consta nos termos da Declaração Internacional sobre Dados Genéticos Humanos ${ }^{2}$.

A técnica da coleta pelo swab é considerada um método não-invasivo. Para se realizar a extração do material biológico para a inserção do perfil genético no banco de dados, a coleta pode ser feita utilizando-se sangue, sêmen, ossos, unhas, dentes e da raiz capilar. Ainda, deverá ser realizada mediante autorização judicial, com motivo justificado e devidamente fundamentado. A autoridade policial, seja ela Estadual ou Federal, só poderá ter acesso aos dados contidos no banco de dados mediante inquérito policial instaurado ou com autorização judicial2,3.

Todas as informações contidas no banco de dados devem ser mantidas em sigilo e apenas tratar a respeito dos perfis genéticos. De acordo com a Lei $12.037 / 2009$, em seu artigo $5^{\circ}$-A, $\S 1^{\circ}$.

"Art. $5^{\circ}$-A, $\S 1^{\circ}$ As informações genéticas contidas nos bancos de dados de perfis genéticos não poderão revelar traços somáticos ou comportamentais das pessoas, exceto determinação genética de gênero, consoante as normas constitucionais e internacionais sobre direitos humanos, genoma humano e dados genéticos"1.

O DNA, ou ácido desoxirribonucleico, é a molécula que contém as informações genéticas de cada ser humano, podendo ele ser nuclear (22 pares de cromossomos autossômicos + 1 par de cromossomos sexuais $X$ e $Y$ ) ou mitocondrial (DNA circular mantido no interior de organelas chamadas mitocôndrias). Para fins de identificação humana, utiliza-se, principalmente, DNA autossômico cuja análise dá origem ao perfil genético. Adicionalmente, utiliza-se o DNA mitocondrial com finalidade de identificação de linhagem materna, bem como o cromossomo $Y$ para identificação de linhagem paterna ${ }^{4}$.

Dentro de cada molécula de DNA existem regiões compostas por longas sequências de nucleotídeos classificadas como codificantes (éxons) e não-codificantes (íntrons), sendo essas últimas, por vezes, denominadas DNA lixo. Nos íntrons geralmente são encontrados os STRs (Short Tandem Repeats), ou microssatélites, que são os ideais para fragmentos pequenos de DNA, sendo capaz de individualizar cada pessoa ${ }^{4}$. Os STRs, ou microssatélites, são sequências constituídas por repetições de uma unidade de dois a seis nucleotídeos, arranjadas consecutivamente, gerando repetições in tandem que variam de acordo com o tamanho de repetições, e se classificam quanto à extensão da unidade de repetição. Os microssatélites representam cerca de 3\% do genoma humano (International Human Genome Sequencing Consortium) ${ }^{5,6}$. 0 tamanho reduzido dos STRs permite que amostras encontradas em menores quantidades de DNA (<350 pb), ou que apresentem alto grau de degradação, possam ser classificadas indicando se pertence à vítima ou a um possível suspeito ${ }^{7}$.

A Genética Forense é um ramo da Biologia de suma relevância que vem sendo constantemente atualizada, evoluindo em métodos e processos analíticos. É uma ciência que, cada vez mais, tem demonstrado à sociedade uma das vertentes do trabalho do perito criminal, sendo importante ressaltar a necessidade de isolamento do local de crime e preservação do material genético para que não ocorra contaminação ou degradação do DNA.

Neste contexto, o presente trabalho tem como objetivo demonstrar a importância da criação do Banco de Dados de Perfis Genéticos na esfera criminal, bem como os seus benefícios para a sociedade, e determinar o papel da Genética Forense na elucidação de crimes. A escolha deste tema se deu pelo crescente número de casos solucionados por meio do exame de DNA, tornando este um assunto de extrema relevância.

\section{METODOLOGIA}

O presente estudo foi realizado utilizando informações extraídas de vinte artigos científicos que podem ser encontrados nos Relatórios da Rede Integrada de Banco de Perfis Genéticos (RIBPG), no Manual de Procedimentos Operacionais da RIBPG, no SciELO, na Revista Brasileira de Criminalística, na Revista da Associação Nacional dos Peritos Criminais Federais (APCF), no site do Planalto Federal, em livros e na própria Lei 12.654/12.

\section{RESULTADOS E DISCUSSÃO}

Um banco de dados de DNA pode ser classificado por dois critérios: pela sua finalidade e pelo seu conteúdo. Pela sua finalidade, pode ser geral, pois armazena informações genéticas de toda a população; podem ser profissionais, quando incluem profissionais de risco cujas amostras consentidas só serão analisadas em casos de necessidade; e, por fim, podem ser com finalidade forense ou judicial que, por sua vez, serão criminais ou cíveis. $O$ outro critério é pelo seu conteúdo, onde podem-se conter dados alfanuméricos, DNA extraído ou material biológico ${ }^{3,8}$.

Um banco de dados, no sentido literal, é aquele que contém apenas dados alfanuméricos inseridos em um su- 
porte de informática. Esses dados contêm números e letras capazes de identificar uma pessoa dentre as demais. Sua classificação quanto à finalidade pode ser geral, profissional, forense ou judicial, conforme descrito anteriormente ${ }^{3,8}$. O Banco de Dados Forense Civil tem como propósito, única e exclusivamente, a identificação de pessoas desaparecidas, comparando-se o perfil de DNA de pessoas desaparecidas (restos cadavéricos) com o perfil genético dos supostos familiares $^{8}$. Já o Banco de Dados Forense Criminal tem como propósito ajudar na resolução de questões relacionadas à identificação criminal quando do cruzamento de informações genéticas coletadas em locais de crime e amostras biológicas de condenados ou suspeitos ${ }^{3}$.

Por meio do Banco de Perfis Genéticos, além de se poder condenar alguém por ter cometido algum delito, interligar crimes interestaduais ou cometidos em outros países, também é possível reavaliar condenações questionáveis podendo, assim, inocentar um indivíduo que foi preso injustamente.

Como exemplo, cita-se o caso em que um cidadão americano chamado Robert Clark foi condenado por estupro em maio de 1982. Ele foi preso por ter sido visto andando pela cidade com o carro da vítima e por não saber explicar como o adquiriu. Seu material genético não foi testado naquele momento. Em dezembro de 2003, uma organização sem fins lucrativos dos Estados Unidos, denominada Innocence Project, solicitou um teste de DNA com amostra coletada da vítima, 22 anos antes ${ }^{9}$.

O resultado da análise comparativa demonstrou que Robert Clark era inocente. Ele passou 21 anos cumprindo pena na prisão por um crime que não cometeu, sendo libertado após essa constatação. O DNA do sêmen encontrado na vítima pertencia a Tony Arnold que já havia sido condenado por crime de violência sexual em 1985 e tinha seu perfil genético armazenado no Banco de Perfis Genéticos dos Estados Unidos ${ }^{9}$.

Essa e inúmeras outras histórias de pessoas inocentes condenadas indevidamente confirmaram a importância de se existir o Banco de Perfis Genéticos, evitando-se, assim, equívocos quanto à autoria de crimes, permitindo a aplicabilidade penal de forma propícia.

Para que as amostras sejam inseridas no Banco de Perfis Genéticos, elas passam por diversas etapas laboratoriais que vão desde a coleta da amostra até a análise estatística. Cada etapa é muito importante. Um erro pode acarretar resultados duvidosos e comprometer a conclusão do caso. Após a coleta da amostra, vem a extração do DNA, sendo o primeiro passo físico-químico, onde se utilizam métodos como resina chelex, método orgânico ou o papel FTA (Flinders Technology Associates). A extração orgânica era utilizada na Genética Forense por ser de baixo custo e pelo seu alto grau de pureza ${ }^{10}$, porém, está em desuso e vem sendo aplicada apenas em situações pontuais. Atualmente, o processo utilizado na extração de DNA é o automatizado, com o auxílio de esferas magnéticas revestidas de sílica, oferecendo risco mínimo de contaminação cruzada. Neste método, as cé- lulas sofrem lise por um buffer e em pH ácido quando, então, pequenas esferas de resina magnética ligam-se ao DNA e um imã atrai essas esferas para o lado ou base do tubo para separar o DNA das impurezas ${ }^{6}$.

A extração do DNA pode acontecer a partir de amostras de sangue, esfregaços bucais, saliva, ossos, dentes, tecidos, órgãos, fios de cabelo, sêmen, dentre outros materiais biológicos. Após a coleta do material biológico, o DNA da amostra deverá ser separado de outras substâncias celulares antes de ser examinado ${ }^{10,11}$. Entretanto, para a inserção do perfil genético no banco de dados da RIBPG, o método de coleta é o swab oral, sendo um procedimento padrão comum ${ }^{12}$.

A terceira etapa é a amplificação do DNA onde a análise de STRs é feita por meio da PCR com o auxílio de primers específicos, sendo variável a quantidade de marcadores genéticos que muda de acordo com os sistemas alélicos multiplex comerciais usados em cada laboratório, fornecendo resultados para mais de 20 loci STRs autossômicos e 23-27 loci do cromossomo Y. A PCR ocorre em três etapas, sendo elas: desnaturação, hibridização e polimerização. Todas essas etapas ocorrem dentro de um termociclador. Na desnaturação, a molécula de DNA é aquecida a uma temperatura de $90^{\circ} \mathrm{C}$, rompendo, assim, as pontes de hidrogênio da dupla hélice. Em seguida, acontece a hibridização dos primers em uma temperatura de 45 a $72^{\circ} \mathrm{C}$. A última etapa da amplificação é a polimerização. Nesta etapa, a enzima DNA Polimerase catalisa a extensão da fita, seguindo o sentido $5^{\prime} \rightarrow 3^{\text {'11-13. }}$.

"A técnica da reação em cadeia da polimerase (PCR) permite a amplificação do DNA in vitro, utilizando-se reações enzimáticas canalizadas pela polimerase, uma enzima termoestável"14.

Após a amplificação, obtém-se o perfil genético. Neste estágio é realizada uma eletroforese capilar (CE) que ocorre dentro de um sequenciador automático onde as amostras são injetadas pelo capilar, recorrendo à aplicação de voltagem. Essa voltagem faz com que as moléculas negativas migrem pelo capilar do ânodo (polo negativo) para o cátodo (polo positivo). Dessa forma, fragmentos de DNA são identificados por meio de uma fluorescência e são separados de acordo com seu peso molecular. Importante ressaltar que a eletroforese capilar é muito usada na Genética Forense por permitir que grandes quantidades de amostras sejam analisadas de forma automatizada utilizando, dessa forma, quantidades menores da amostra durante o processo de injeção $0^{11}$.

Por último, ocorre a análise estatística onde serão analisados os resultados das amostras e inseridos os perfis genéticos na RIBPG, exigindo-se a genotipagem de um número mínimo de marcadores genéticos padronizados, como recomenda o Manual de Procedimentos Operacionais da RIBPG ${ }^{12}$. Os treze marcadores CODIS são altamente polimórficos, sendo eles: CSF1PO; D3S1358; D5S818; D7S820; D8S1179; D13S317; D16S539; D18S51; D21S11; FGA; TH01; TPOX; vWA, que são considera- 
dos marcadores genéticos requeridos. São aceitos, também, os seguintes marcadores: D2S1338, D19S433, Penta E, Penta D, D10S1248, D22S1045, D1S1656, D12S3391 e D2S441.

Os loci genéticos são suficientes para individualizar pesso- as e para realizar a identificação por meio de parentesco. Com os alelos, é possível fazer vinculações genéticas como irmandade, maternidade e paternidade ${ }^{11}$. Na Figura 1, demonstra-se a obtenção do perfil genético.

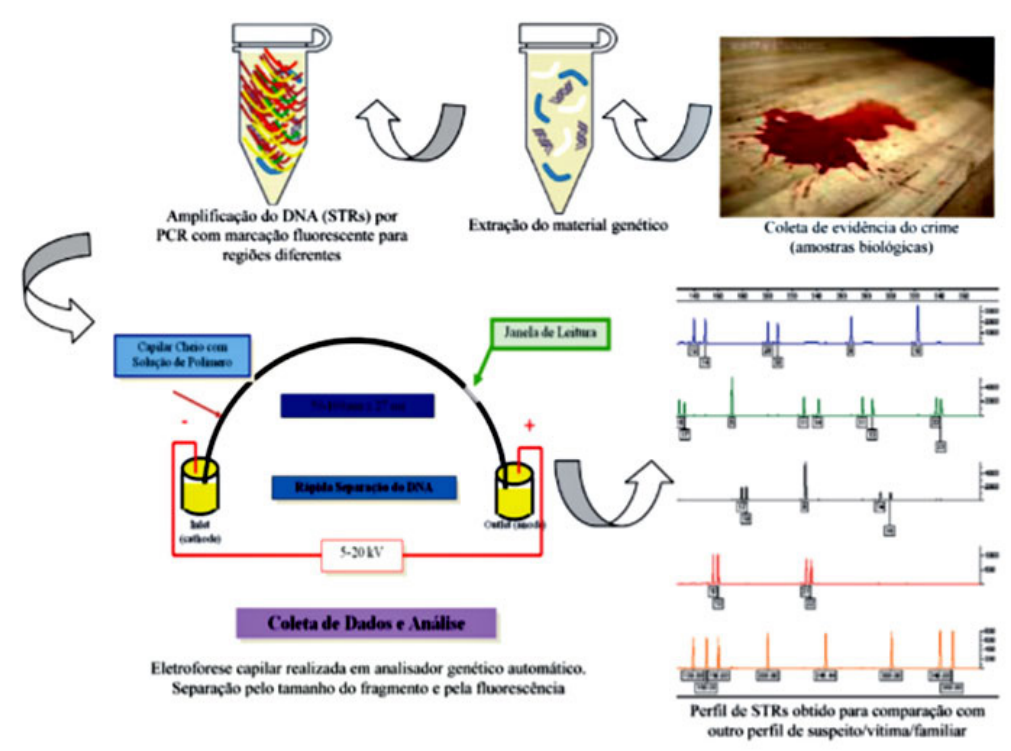

Figura 1: Obtenção do perfil genético ${ }^{13}$.

O polimorfismo na molécula de DNA se refere ao número de alelos diferentes específicos de cada região molecular que são muito empregados na identificação humana por apresentar uma baixa taxa de mutação, maior frequência de heterozigotos (acima de 90\%), menor tamanho e maiores variações de repetições da sequência polimórfica ${ }^{15}$.

A Genética Forense é de extrema importância para a esfera criminal. O DNA é a ferramenta mais importante da ciência moderna e colocado à disposição da justiça para combater crimes e a impunidade ${ }^{16,17}$. Desde 2014, são publicados relatórios semestrais relatando os dados encontrados por meio da RIBPG ${ }^{18-20}$.

Em maio de 2020, foi publicado o XII relatório semestral da RIBPG onde mostrou a porcentagem de distribuição, por categoria, de perfis genéticos contidos no banco de dados. A maior porcentagem é de perfis genéticos de condenados $(78,35 \%)$, seguido de vestígios (14,67\%), restos mortais não identificados $(2,73 \%)$ e familiares de pessoas desaparecidas $(2,63 \%)^{19}$.

As categorias com menor porcentagem no banco de dados são de suspeitos $(0,93 \%)$, decisões judiciais $(0,47 \%)$, restos mortais não identificados $(0,47 \%)$, pessoas de identidade desconhecida $(0,3 \%)$ e referências diretas de pessoa desaparecida $(0,3 \%)^{19}$.

Até 0 ano de 2019, o Banco de Perfis Genéticos auxiliou 852 investigações, teve 926 coincidências, sendo 59\% dessas envolvendo crimes sexuais, de acordo com dados fornecidos pela Rede Integrada de Bancos de Perfis Genéticos. No novo relatório da RIBPG, até o dia 28 de maio de 2020, foi apresentado ao poder público 1928 coincidências confirmadas, sendo 1508 entre vestígios e 420 entre vestígio e indivíduo cadastrado criminalmente, e auxiliou 1406 investigações. Desse modo, observase o quanto o banco de dados vem corroborando na elucidação de crimes, indicando, assim, um aumento na eficiência dos bancos de dados do país ${ }^{18}$.

Outro dado importante informado no relatório de maio de 2020 , foram as coincidências registradas por tipo de crime. De acordo com os dados coletados, $58 \%$ das coincidências envolvendo os vestígios estão relacionadas a crimes sexuais, e 38\% a crimes contra o patrimônio. Na Figura 2, a distribuição das coincidências vestígio $\mathrm{x}$ vestígio registradas nos bancos de perfis genéticos é apresentada de acordo com a natureza dos crimes. 


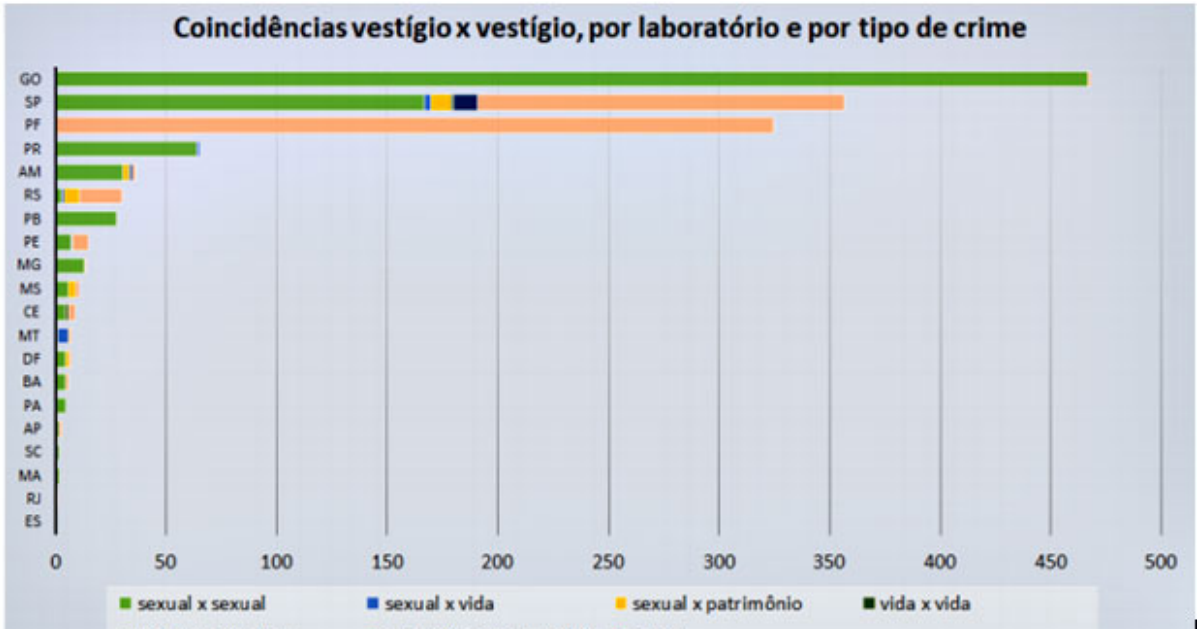

Figura 2: Distribuição das coincidências vestígio x vestígio, segundo a natureza do crime, por Unidade da Federação ${ }^{19}$.

Já no registro das coincidências entre vestígios e indivíduos cadastrados criminalmente, apontaram serem mais comuns em crimes sexuais $(52 \%)$ e crimes contra o patrimônio $(40 \%)$, de acordo com o mesmo relatório da RIBPG de maio de 2020.
Na Figura 3, a distribuição das coincidências vestígio x indivíduo cadastradas criminalmente no banco de perfis genéticos é apresentada de acordo com a natureza dos crimes.

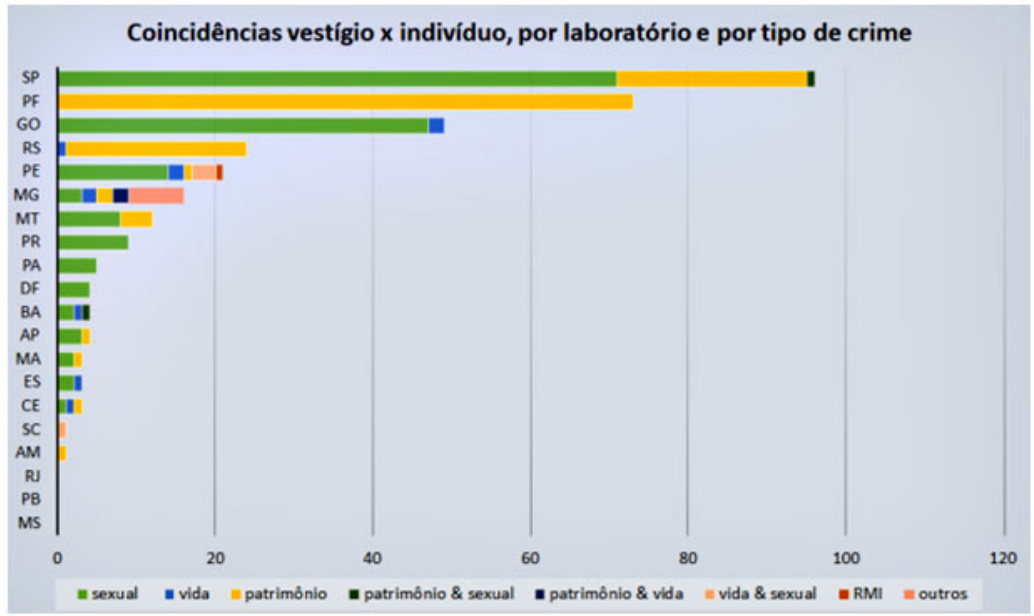

Figura 3: Distribuição das coincidências vestígio x indivíduo cadastrado criminalmente, segundo a natureza do crime, por Unidade da Federação ${ }^{19}$.

No ano de 2020 foi publicado o XIII relatório semestral da RIBPG, referente ao período compreendido entre os meses de maio a novembro de 2020 , onde constam atualizações de dados estatísticos e resultados do Banco de Perfis Genéticos. Sobre a distribuição das categorias de perfis genéticos existentes no BNPG, verificou-se uma maior proporção de perfis genéticos de condenados $(75,67 \%)$, seguido de vestígios $(16,56 \%)$, restos mortais não identificados $(3,28 \%)$ e familiares de pessoas desaparecidas $(2,75 \%)$. As categorias com menor proporção são as de indivíduos identificados criminalmente $(0,95 \%)$, decisões judiciais $(0,46 \%)$, restos mortais identificados $(0,27 \%)$, pessoas de identidade desconhecida $(0,03 \%)$ e referências diretas de pessoa desaparecida $(0,03 \%)^{20}$.

Ainda de acordo com este relatório, até 28 de novembro de 2020 a RIBPG apresentou ao poder público 2662 coincidências confirmadas, sendo 2088 entre vestígios e 574 entre vestígio e indivíduo cadastrado criminalmente, e auxiliou 1977 investigações. Com relação às coincidências registradas por crimes, $65 \%$ das coincidências envolvendo vestígios estão relacionadas a crimes sexuais e $31 \%$ a crimes contra o patrimônio. Já as coinci- 
dências entre vestígios e indivíduos cadastrados individualmente são mais comuns em crimes sexuais (56\%) e crimes contra o patrimônio $(34 \%)^{20}$. Na Figura 4, é possível observar a distribuição das coincidências vestígio $\mathrm{x}$ vestígio registradas nos bancos de perfis genéticos de acordo com a natureza dos crimes.

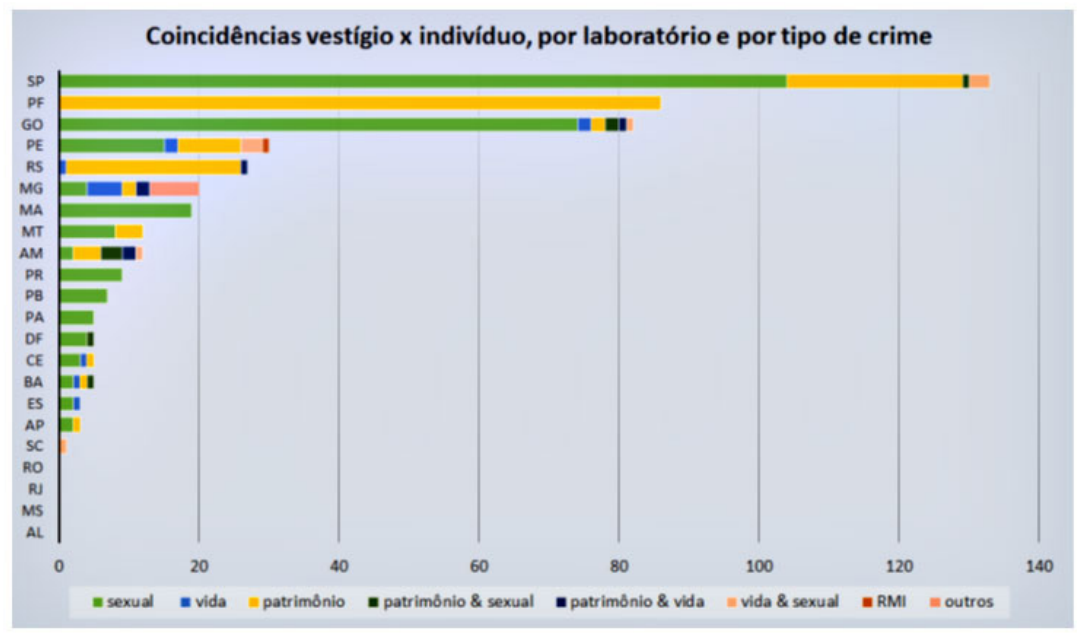

Figura 4: Distribuição das coincidências vestígio x indivíduo cadastrado criminalmente, segundo a natureza do crime, por laboratório ${ }^{20}$.

A publicação desses relatórios evidenciou consideráveis registros de como o Banco de Perfis Genéticos auxilia a Perícia Criminal e as investigações, sendo mais que notável sua relevância para a sociedade. De acordo com o relatório de novembro de 2020, a RIBPG é formada por 22 laboratórios de genética forense vinculados às unidades de perícias estaduais, do DF e federal ${ }^{20}$.

Desta forma, destaca-se a importância de um banco de dados para o meio criminal e para a sociedade como um todo, uma vez que colabora com as questões relacionadas à autoria de crimes elucidando a participação dos agentes envolvidos, bem como na identificação de pessoas desaparecidas.

\section{CONCLUSÃO}

Com o presente trabalho, evidencia-se a grande importância que o Banco de Perfis Genéticos tem para a esfera forense e o quanto pode atuar no controle de ações criminosas elucidando sua verdadeira autoria, como nos casos em que se comprova a inocência de indivíduos presos indevidamente. É, também, com o exame de DNA que se individualiza um ser humano dentre tantos outros, resolvendo questões relacionadas às pessoas desaparecidas.

\section{REFERÊNCIAS}

1. Brasil. Lei $n^{0} 12.654$, de 28 de maio de 2012. Altera as Leis nº 12.037, de $1^{\circ}$ de outubro de 2009, e 7.210, de 11 de julho de 1984 - Lei de Execução Penal, para prever a coleta de perfil genético como forma de identificação criminal, e dá outras providências. Diário Oficial da União. 28 mai 2012.

2. UNESCO - United Nations Educational, Scientific and Cultural Organization. Declaração internacional sobre os dados genéticos humanos. Portugal; 2004 [acesso em: 24 de jan. 2020]. Disponível em: http://bvsms.saude.gov.br/bvs/publicacoes/declaracao_inter_ dados_genericos.pdf.

3. Nicolitt AL, Wehrs CR. Intervenções corporais no processo penal e a nova identificação criminal: Lei 12.654/2012. Rio de Janeiro: Elsevier; 2015.

4. Decanine D. O Papel de marcadores moleculares na genética forense. Rev. Bras. Crimin. 2016;5(2):18-27.

5. Valle GS. Análise de marcadores forenses (STRs e SNPs) rotineiramente empregados na identificação humana utilizando sequenciamento de nova geração [Dissertação de Mestrado]. Ribeirão Preto: Faculdade de Filosofia, Ciências e Letras de Ribeirão Preto; 2018.

6. Dias Filho CR, Rodrigues EL, Malaguini M, Francez PAC, Garrido RG. Introdução à Genética Forense. Campinas: Milennium Editora; 2020.

7. Brito AFS, Pontes AN. Identificação humana por DNA através do banco nacional de perfis genéticos e a quantificação de amostras armazenadas. Rev. Bras. Crimin. 2020;9(2): 76-84.

8. Bonaccorso NS. Aspectos técnicos, éticos e jurídicos relacionados com a criação de bancos de dados criminais de DNA no Brasil [Tese de Doutorado]. São Paulo: Faculdade de Direito da Universidade de São Paulo; 2010.

9. Lima HB. DNA x Criminalidade. Perícia Federal. 2008;26:8-11.

10. Leite VS, Batista MIHM, Carvalho MVD; Sobral APV. Uso das técnicas de biologia molecular na genética forense. Derecho y 
Cambio Social. 2013;34:1-18.

11. Butler JM. Forensic DNA typing: biology, technology, and genetics of STR markers. Cambridge: Elsevier Academic Press; 2005. 12. RIBPG. Manual de procedimentos operacionais da RIBPG (versão 4) - Resolução n¹4. Brasília (DF): Comitê Gestor RIBPG; 2019 [Acesso em: 16 de mar. 2021]. Disponível em: https://www. justica.gov.br/sua-seguranca/seguranca-publica/ribpg/manual.

13. Garrido RG. Evolução dos processos de identificação humana: das características antropométricas ao DNA. Genética na Escola. 2009;5(2):38-40.

14. Barbosa CA, Faria RA, Malaghini M, Nogozzeky KA. Aplicação de mini-strs non-codis na casuística forense. In: Anais do 24. Congresso Brasileiro em Engenharia Biomédica; 13-17 out 2014; Uberlândia. Uberlândia (MG): Sociedade Brasileira de Engenharia Biomédica (BR); 2014.

15. Pacheco AC. Emprego de Mini-STRs "non-CODIS" em amostras biológicas de DNA forense. [Dissertação de Mestrado]. São Paulo: Instituto Butantan, Universidade de São Paulo; 2010.

16. Smarra A, Paradela E, Figueiredo A. Genética forense no Brasil. Scientific American Brasil. Ago. 2006.
17. Paes R, Ribeiro I. Importância do DNA forense para a biologia moderna: uma revisão. Ensaios Cienc., Cienc. Biol. Agrar. Saúde. 2016;20(1):30-37.

18. Ministério da Justiça e Segurança Pública. X Relatório da rede integrada de bancos de perfis genéticos (RIBPG). Brasília (DF): RIBPG; 2019 [acesso em 24 de jan. 2020]. Disponivel em: https:// www.maispb.com.br/wp-content/uploads/2019/06/X-RELATORIODA-REDE-INTEGRADA-DE-BANCOS-DE-PERFIS-GENETICOS -RIBPG.pdf.

19. Ministério da Justiça e Segurança Pública. XII Relatório da rede integrada de bancos de perfis genéticos (RIBPG). Brasília (DF): RIBPG; 2020 [acesso em 04 de ago. 2020]. Disponível em: https://www.justica.gov.br/sua-seguranca/seguranca-publica/ribpg/ relatorio/xii-relatorio-da-rede-integrada-de-bancos-de-perfis-geneticos.pdf/view.

20. Ministério da Justiça e Segurança Pública. XIII Relatório da rede integrada de bancos de perfis genéticos (RIBPG). Brasília (DF): RIBPG; 2020 [acesso em 25 de dez. de 2020]. Disponível em: https://www.justica.gov.br/sua-seguranca/seguranca-publica/ ribpg/relatorio-interativo/xiii-relatorio-da-ribpg. 